Editorial

\title{
La revolución de la radiología de precisión: entre la dinámica y la inercia
}

\author{
Hugo J. Paladini ${ }^{1,2,3}$ \\ ${ }^{1}$ Médico coordinador del área Cuerpo en el servicio de Tomografía \\ Computada y Resonancia Magnética en el Hospital Universitario de la \\ Fundación Favaloro, Buenos Aires, Argentina \\ 2 Jefe de Servicio de Diagnóstico por Imágenes de la Clínica de Nefrología, \\ Urología y Enfermedades Cardiovasculares, Santa Fe, Argentina \\ ${ }^{3}$ Miembro del Comité de Redacción de la Revista Argentina de Radiología \\ Rev Argent Radiol 2019;83:93-94.
}

Desde hace años se viene planteando que la medicina de precisión (MP) tendrá gran impacto en los sistemas de salud mundial. Pero, ¿sabemos a qué hace referencia ese término? $\mathrm{Y}$ desde nuestra especialidad, ¿somos partícipes?

\section{Definiciones y la necesidad de la evolución de la radiología}

Se define a la MP como: "...la adaptación del tratamiento médico a las características individuales de cada paciente, que abarca la capacidad de clasificar a los individuos en subpoblaciones que difieren en su susceptibilidad a una enfermedad particular, en la biología y/o pronóstico de aquellas enfermedades que pueden desarrollarse, o en su respuesta a un tratamiento específico". ${ }^{1}$ Queda claro que el diagnóstico por imágenes tiene un rol de importancia en ese nuevo paradigma, afirmación que, ya en el año 2011, promovía la Sociedad Europea de Radiología. ${ }^{2}$

El rol de clasificar subpoblaciones en nuestro trabajo lo vemos a diario, por ejemplo usando la TC para realizar screening de enfermedades preclínicas. No obstante, esas clasificaciones no dan una solución definitiva a muchos de los problemas que surgen con los avances. Por ejemplo, en la inmunoterapia, los criterios morfológicos para evaluar respuesta (como RECIST), no resultan suficientes.

\section{Una potencial respuesta}

Los avances en otras ramas de la medicina obligan a los radiólogos a buscar nuevas formas de afrontar el desafío. Por fortuna, la interacción de la radiología con especialidades como la física, matemática, bioinformática y bioingenería nos permite contar con herramientas novedosas para aumentar nuestra contribución a la MP brindando información cuantitativa, libre de casi toda subjetividad y que, debido a su compleja organización, se encuentra oculta para el ojo humano.
A 15 años de haber sido descifrado el genoma humano, la genética es de las ramas que más moviliza la revolución hacia la MP, y las imágenes pueden ser un complemento ideal. Para comprenderlo, debemos conocer primero el concepto de "radiómica", es decir, "proceso de obtención de grandes volúmenes de datos extraídos de las imágenes de rutina, utilizando algoritmos de caracterización de datos, automáticos o semiautomáticos". ${ }^{3}$ Esos datos, pueden ser extraídos de prácticamente todas las modalidades de imágenes, demostrando ser útiles como biomarcadores con valor diagnóstico y pronóstico. De la combinación de la radiómica con la genómica surge la radiogenómica, como herramienta potenciada de gran precisión. ${ }^{4}$

\section{Obstáculos: sobre estándares, depreciación de las imágenes y ausencia de políticas nacionales}

Si bien en la actualidad abundan los trabajos que publican potenciales usos de los biomarcadores, la radiómica y la radiogenénomica, todavía existen ciertas barreras que impiden que sean utilizados en la práctica clínica diaria.

Uno de los problemas principales que enfrenta la radiómica es su falta de estandarización, algo que despertó la preocupación de sociedades internacionales de radiología, que crearon grupos como "Quantitative Imaging Biomarkers Alliance","European Imaging Biomarkers Alliance" para asistir a la sociedad médico/científica en la homogeneización de la investigación de biomarcadores en imágenes. ${ }^{4}$

Otra barrera es el desconocimiento de nuestros especialistas acerca del poder de la información con la que trabajamos. Las grandes empresas no médicas, son conscientes del poder de los datos, aprovechando hasta el último ápice de información que recaban para potenciar ventas y ganancias. ¿Cuánta información acumulamos en nuestros PACS esperando que sea borrada en el próximo mantenimiento y cuánta pasa por nuestros

Copyright (c) 2019, Sociedad Argentina de Radiología. Publicado por Thieme Revinter Publicações Ltda., Rio de Janeiro, Brazil. Todos los derechos reservados.

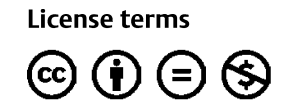

Hugo J. Paladini, MD, Hospita

Universitario de la Fundación

Favaloro, Buenos Aires, Argentina

(e-mail: hugojpaladini@

hotmail.com).
DOI https://doi.org/ ISSN 1852-9992. 
servicios sin siquiera registrarla, (información con potencial para mejorar la salud y asistencia de nuestros pacientes)?

De todas formas, el desconocimiento no es solo del radiólogo. La MP solo es realizable con enormes volúmenes de información estandarizada y representativa de grandes poblaciones. No contar con dichas bases y tratar de utilizar series de casos con el objetivo de definir biomarcadores para su uso en políticas de salud nacional puede dar resultados poco convincentes y faltos de robustez. Eso marca otro desafío y pone el foco sobre la necesidad de la participación también de un Estado que actúe activamente como facilitador en esos proyectos. Algo que Estados Unidos comprendió ya en el 2015, fundando una iniciativa de MP ("All of US"), que incluye millones de personas de las cuales se obtendrá información durante más de 10 años, a ser evaluada con el propósito de orientar los sistemas de salud basados en datos. ${ }^{5}$

En nuestro país carecemos de políticas y estándares elementales al respecto. Un ejemplo básico es la desigualdad en el trato de las imágenes por parte de los diferentes centros (públicos o privados). Los médicos derivantes que reciben a los pacientes en sus consultorios ven desfilar todos los soportes existentes en el mercado para presentar los estudios que informamos: $C D$, placas o impresiones en papel A3/A4, portales virtuales o hasta simples fotocopias de informes sin imágenes. Es un dolor de cabeza incluso para nosotros cuando, por ejemplo, se nos solicita una segunda opinión.

¿Pero cómo podemos comenzar a ser actores en el nuevo paradigma? Para empezar, debemos conocer que contamos con una gran ventaja respecto a otras especialidades: los equipos con que trabajamos nos entregan, de cada paciente, información digitalizada y estandarizada (DICOM). Si agregáramos a cada estudio informes digitales estandarizados (con plantillas propuestas por las sociedades) e incluyésemos en nuestros servicios nuevos protagonistas (bioingenieros, ingenieros en sistemas) que comprendan el trato de la información, se estaría dando un inmenso avance.

Si bien nuestro país afronta una crisis económico social, es necesario que nos comprometamos en la adopción de esas nuevas herramientas asegurando su existencia (desarrollándolas), su confiabilidad (cuestionándolas y estandarizándolas) y su universalidad (adaptándolas una vez aprobadas).

Contribuiremos así, junto al resto del equipo multidisciplinario, a brindar a los pacientes una verdadera medicina de precisión.

\section{Bibliografía}

1 National Research Council, Division on Earth and Life Studies, Board on Life Sciences, et al. Toward precision medicine: building a knowledge network for biomedical research and a new taxonomy of disease. Washington, DC: The National Academies Press; 2011

2 European Society of Radiology. Medical imaging in personalised medicine: a white paper of the research committee of the European Society of Radiology (ESR). Insights Imaging 2011;2(06):621-630

3 Giardino A, Gupta S, Olson E, et al. Role of Imaging in the Era of Precision Medicine. Acad Radiol 2017;24(05):639-649

4 Ranschaert E, Morzov S, Algra P. Artificial Intelligence in Medical Imaging: Opportunities, Applications and Risks. Switzerland: Springer; 2019

5 Ginsburg GS, Phillips KA. Precision Medicine: From Science To Value. Health Aff (Millwood) 2018;37(05):694-701 